\title{
ИНСТРУМЕНТЫ РЕАЛИЗАЦИИ СТРАТЕГИЧЕСКИХ ИНИЦИАТИВ ВЫСШЕГО УЧЕБНОГО ЗАВЕДЕНИЯ В ЦЕЛЯХ ПОВЫШЕНИЯ КАЧЕСТВА ОБРАЗОВАТЕЛЬНОГО ПРОЦЕССА
}

\author{
(c) 2018 Николаева Елена Анатольевна \\ кандидат социологических наук, доцент \\ кафедра иностранных языков № 3 \\ Российский экономический университет им. Г.В. Плеханова» \\ 115093, г. Москва, Стремянный пер., 36 \\ E-mail:yoltash82@mail.ru \\ (C) 2018 Кузнецова Юлия Андреевна \\ кандидат экономических наук, доцент \\ кафедра иностранных языков № 3 \\ Российский экономический университет им. Г.В. Плеханова \\ 115093, г. Москва, Стремянный пер., 36 \\ E-mail: yulia_success@mail.ru \\ (c) 2018 Агибалова Елена Леонидовна \\ кандидат филосовских наук, доцент \\ заведующая кафедрой иностранных языков № 3 \\ Российский экономический университет имени Г. В. Плеханова \\ 115093, г. Москва, Стремянный пер., 36 \\ E-mail:kafmkk@mail.ru \\ (c) 2018 Каржанова Наталья Викторовна \\ кандидат филосовских наук, доцент \\ кафедра иностранных языков № 3 \\ Российский экономический университет имени Г.В. Плеханова \\ 115093, г. Москва, Стремянный пер., 36 \\ E-mail: knatalya11@mail.ru
}

В статье автора приводится попытка разрешения актуальной на сегодняшний день проблемы повышения качества образовательного процесса высшего учебного заведения через призму анализа различных инструментов реализации его стратегических инициатив. Объект исследования - образовательный процесс высшего учебного заведения, а предмет - инструменты реализации стратегических инициатив высшего учебного заведения в целях повышения качества образовательного процесса. Теоретическое и методологическое значение исследования проявляется в развитии соответствующей методической базы инструментария реализации стратегических инициатив высшего учебного заведения, а практическое в возможном повышении эффективности их применения.

Ключевые слова: высшие учебные заведения, стратегические инициативы, образовательный процесс, повышение качества, показатели эффективности деятельности высшего учебного заведения, цели, персонал, инструменты реализации стратегии.

В условиях глобальной модернизации системы высшего профессионального образования в Российской Федерации нарастающую значимость в процессе управления высшим учебным заведением получает качество образовательного процесса. Именно поэтому более 85\% процентов высших учебных заведений в Российской Федерации по состоянию на 01.01.2018 года обо- значили повышение качества образовательного процесса одной из ключевых стратегических целей на ближайшие пять лет (табл. 1). Из таблицы можно увидеть, что указанная цель имеет вторую по величине распространенности рейтинговую позицию (33,90\% из 100 возможных), незначительно уступая лишь привлечению достаточного количества обучающихся. 
Таблица 1. Ключевые стратегические цели высших учебных заведений Российской Федерации по состоянию на 01.01.2018 года

\begin{tabular}{|c|c|}
\hline $\begin{array}{c}\text { Наименование стратегической цели, согласно стратегиям развития } \\
\text { высших учебных заведений }\end{array}$ & $\begin{array}{l}\text { Уровень распространенности } \\
\text { цели,\% }\end{array}$ \\
\hline $\begin{array}{l}\text { Привлечение достаточного количества обучающихся для эффективного } \\
\text { заполнения аудиторного фонда }\end{array}$ & 35,80 \\
\hline Повышение качества образовательного процесса & 33,90 \\
\hline Повышение уровня инновационности обучения & 17,30 \\
\hline $\begin{array}{l}\text { Повышение уровня благосостояния сотрудников высшего учебного } \\
\text { заведения }\end{array}$ & 9,50 \\
\hline $\begin{array}{l}\text { Прочие цели, обозначенные высшими учебными заведениями } \\
\text { в стратегиях своего развития }\end{array}$ & 3,50 \\
\hline Всего & 100,00 \\
\hline
\end{tabular}

Среди инструментов реализации своих стратегических инициатив высшие учебные заведения в Российской Федерации на начало 2018 года использовали следующий набор инструментов, приведенный в табл. 2 .

На рисунке 1 приведены данные по уровню распространенности обозначенных инструментов реализации стратегических инициатив в высших учебных заведениях Российской Федерации на начало 2018 года. Как можно увидеть, более половины анализируемых объектов (в совокупности более 69\% из рассмотренных высших учебных заведений) используют в качестве инструмента реализации своей стратегии систему сбалансированных показателей и ключевые показатели эффективности. Далее следует пирамида достижений, уровень распространённости которой среди высших учебных заведений находится в пределах 21,8\%.

Завершают перечень деловое окно управления и прочие инструменты реализации стратегических инициатив, которые в Российской Фе- дерации в совокупности применяют менее 10\% анализируемых высших учебных заведений.

Ниже в табл. 3 приведены данные по распределению изменений показателей качества образовательного процесса в зависимости от применяемого инструмента реализации стратегии высших учебных заведений в Российской Федерации за последние пять лет.

Данные табл. 3 позволили сделать следующие выводы:

- наибольшие изменения в уровнях показателей качества образовательного процесса высших учебных заведений в Российской Федерации в анализируемый период времени (порядка 70\% респондентов улучшили значения своих показателей в интервале от 60-79\%, при этом результаты $10 \%$ респондентов улучшились плоть до наивысшего из анализируемых значений) имели место для такого инструмента, как «Система сбалансированных показателей»;

- далее следовал инструмент, связанный с ключевыми показателями эффективности, при-

Таблица 2. Инструменты реализации стратегических инициатив высшими учебными заведениями в Российской Федерации на начало 2018 года

\begin{tabular}{|l|l|}
\hline \multicolumn{1}{|c|}{ Наименование инструмента } & \multicolumn{1}{|c|}{ Ключевая особенность инструмента } \\
\hline Система сбалансированных показателей & $\begin{array}{l}\text { Стратегия развития высшего учебного заведения рассматривает- } \\
\text { ся через призму следующих пространств показателей: финансы; } \\
\text { персонал; процессы; инновации и обучение. }\end{array}$ \\
\hline Ключевые показатели эффективности & $\begin{array}{l}\text { Показатели стратегии развития высшего учебного заведения } \\
\text { сгруппированы в более широкий перечень пространств (методо- } \\
\text { логически, инструмент достаточно близок к предыдущему). }\end{array}$ \\
\hline Пирамида достижений & $\begin{array}{l}\text { Инструмент построен на тандеме измерений и достижений в } \\
\text { проекции внутренний и внешней эффективности деятельности } \\
\text { высшего учебного заведения. }\end{array}$ \\
\hline Деловое окно управления & $\begin{array}{l}\text { Комплексный и наглядный инструмент стратегического плани- } \\
\text { рования, основанный на бенчмаркинге процессов и результатов } \\
\text { деятельности высшего учебного заведения. }\end{array}$ \\
\hline Прочие & $\begin{array}{l}\text { Сюда были отнесены такие инструменты реализации страте- } \\
\text { гии, как «Бортовое табло», «Квантовое измерение достижений», } \\
\text { «Измерение достижений компании «Эрнст \& Янг», «джйКейс», } \\
\text { «Катерпиллар», «Комплексный анализ данных» и другие. }\end{array}$ \\
\hline
\end{tabular}




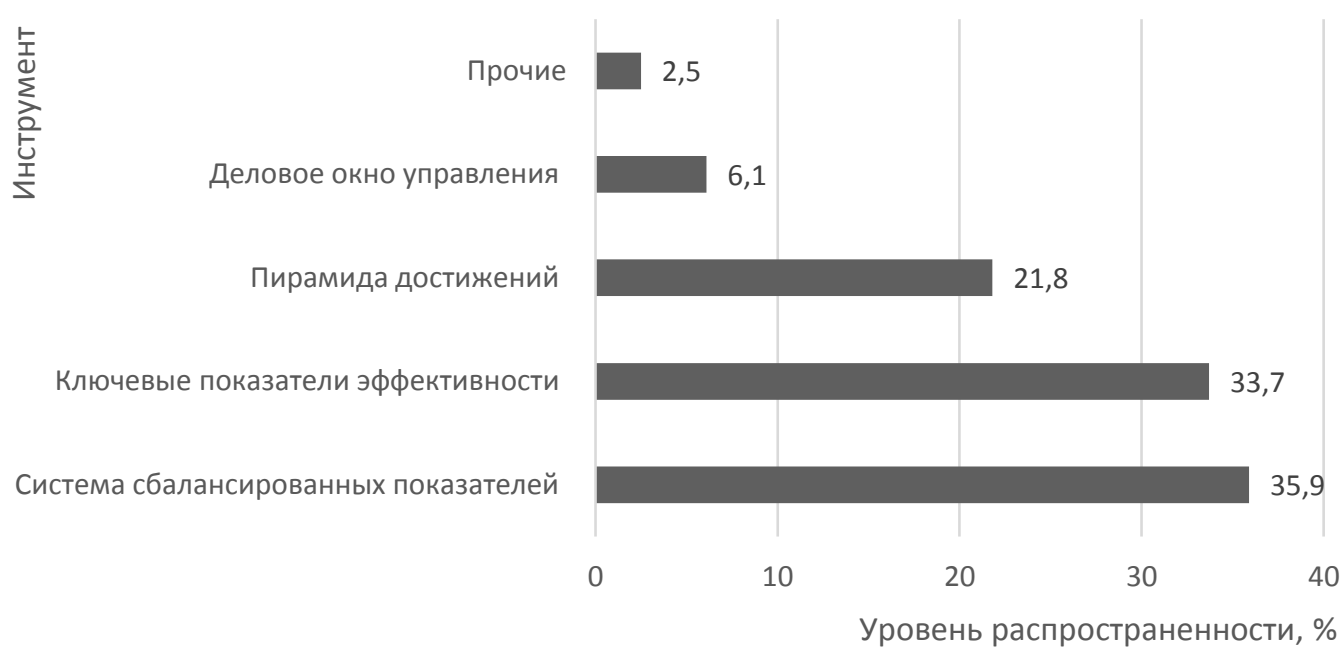

Рис.1. Уровень распространенности инструментов реализации стратегических инициатив в высших учебных заведениях Российской Федерации на начало 2018 года

Таблица 3. Данные по распределению изменений показателей качества образовательного процесса в зависимости от применяемого инструмента реализации стратегии высших учебных заведений в Российской Федерации в 2013-2017 годах в\%

\begin{tabular}{|l|c|c|c|c|c|}
\hline \multirow{2}{*}{ Наименование инструмента } & \multicolumn{5}{|c|}{ Уровень изменения показателей качества } \\
\cline { 2 - 6 } & $0-19$ & $20-39$ & $40-59$ & $60-79$ & $80-100$ \\
\hline Система сбалансированных показателей & & & 20 & 70 & 10 \\
\hline Ключевые показатели эффективности & & 30 & 50 & 20 & \\
\hline Пирамида достижений & 10 & 30 & 60 & & \\
\hline Деловое окно управления & 20 & 20 & 50 & 10 & \\
\hline Прочие & 35 & 25 & 40 & & \\
\hline
\end{tabular}

농

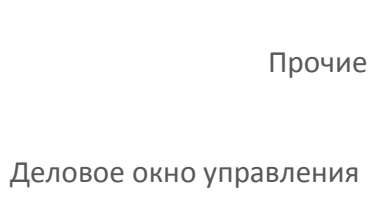

Пирамида достижений

Ключевые показатели эффективности

Система сбалансированных показателей

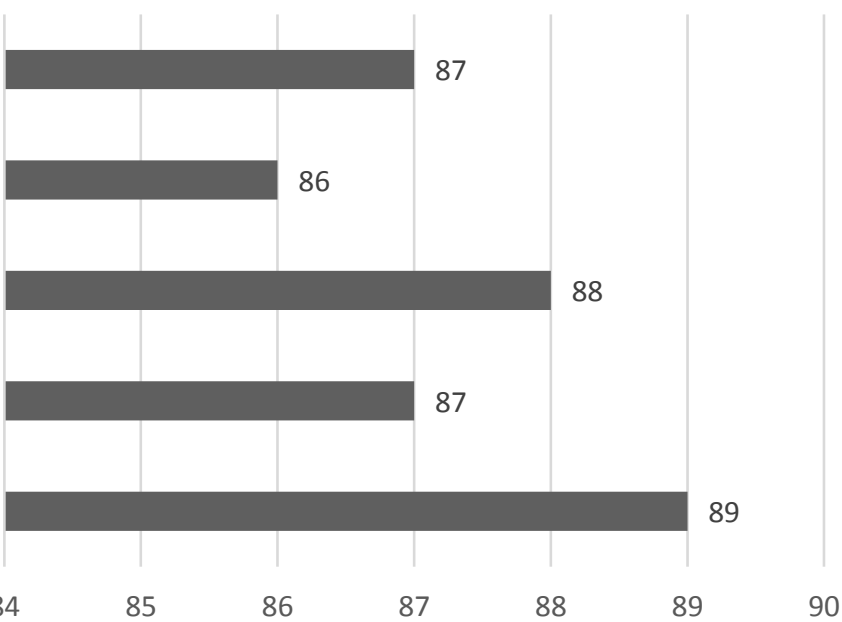
84
$85 \quad 86$
Коррелация, ед.

Puc. 2. Коэффициенты корреляции анализируемых инструментов с достигнутыми уровнями изменений показателей качества высших учебных заведений в Российской Федерации в 2013-2017 годах 
менение которого позволило высшим учебным заведениям Российской Федерации улучшить значения показателей, отображающих качество учебного процесса вплоть до 79\%. Однако, большая часть респондентов (порядка $50 \%$ и $30 \%$ соответственно) здесь расположилась в интервале изменений от 40 до 59\% и от 20 до 39\%. При этом лишь 20\% высших учебных заведений достигли изменений в интервале от 60 до 79\%;

- применение инструмента реализации стратегических инициатив под названием «Пирамида достижений» позволило высшим учебным заведениям в Российской Федерации повысить качество образовательного процесса вплоть до 59\% (данная позиция имела место у подавляющего числа респондентов). Чуть менее трети от всех респондентов в данной группе повысила уровень своих показателей качества образовательного процесса до 39\% включительно. Некоторая часть респондентов (порядка 10\%) приходилась на интервал от 0\% до 19\% изменений;

- более хаотичное распределение изменений показателей анализируемой категории в высших учебных заведениях Российской Федерации в 2013-2017 годах (20\% респондентов в данной группе достигли 19\% уровня изменений, аналогичное количество достигло 39\% уровня,
$50 \%$ достигло уровня в 59\%, а $10 \%$ в $79 \%$ ) имело место для инструмента «Деловое окно управления»;

- применение прочих инструментов реализации стратегии в целях повышения уровня качества образовательного процесса в высших учебных заведениях в Российской Федерации позволило достичь отметки максимум в 59\% из ста возможных.

Коэффициенты корреляции анализируемых инструментов с достигнутыми уровнями изменений показателей качества высших учебных заведений в Российской Федерации в 2013-2017 годах приведены на рисунке 2.

Из рисунка можно увидеть, что выводы по всем без исключения инструментам являются в достаточной мере обоснованными (их коэффициенты корреляции равны или превышают пороговое значение в 0,86 единиц).

Таким образом, можно сделать вывод, что для реализации стратегических инициатив в целях повышения качества образовательного процесса в будущем высшим учебным заведениям Российской Федерации целесообразно использовать системы сбалансированных показателей, обладающую наивысшим уровнем эффективности применения.

\section{Библиографический список}

1. Журавлева Ю.А. Высшее образование россиян как фактор готовности к инновационным преобразованиям: региональный аспект // Экономические науки. 2013. № 11. С.129-133.

2. Якуб О.А. Стратегия поведения работников на рынке труда с учетом отраслевой специфики (на примере предприятий оптовой торговли) // Экономические науки. 2015. № 11. С.73-76.

3. Johnsen A. Balanced scorecard: theoretical perspectives and public management implications // Managerial Auditing Journal. 2001. Vol. 16 No. 6, pp. 319-30.

4. Proctor R., Reeve T. and Weeks D. A Triphasic Approach to the Acquisition of Response-Selection Skill // Psychology of Learning and Motivation.1990. Vol. 26, pp. 207-240.

5. Компания Ernst\&Young [Электронный ресурс]: аналитические материалы - Официальный сайт компании Ernst\&Young, 2018. - Режим доступа: http:// www.ey.com/

6. Рейтинговое агентство Эксперт РА [Электронный ресурс]: аналитические материалы.- Официальный сайт рейтингового агентства Эксперт РА, 2018.- Режим доступа: https://raexpert.ru 